\title{
LA SANTA FAZ, IMAGEN DEVOCIONAL, EN LOS CONVENTOS DE TOLEDO.
}

\author{
PILAR FERNÁNDEZ VINUESA \\ AIDA ANGUIANO DE MIGUEL \\ Universidad Complutense de Madrid
}

\section{Resumen}

El objetivo de esta investigación es dar a conocer las distintas iconografías y estilos pictóricos de la Santa Faz de los conventos de Toledo. Obras, en ocasiones, anónimas e inéditas. Se lleva a cabo un estudio comparativo de las distintas versiones de esta imagen devocional desde el segundo tercio del siglo XVI a la cuarta década del siglo XVII.

Se analizan las diferencias del modelo iconográfico manierista de El Greco, frente a dos pintores barrocos europeos- Zurbarán, Philippe de Champaigne- y al estilo y la técnica del lienzo del convento de Madres Benitas. La indagación, en archivos y fuentes bibliográficas, aporta nuevos datos sobre el parentesco y la relación del coleccionista Andres Passano de Haro con Génova; y respalda la atribución de la Santa Faz del convento de Madres Benitas a Rubens o Van Dick.

\section{Palabras clave}

Verónica, iconografía, manierismo, barroco, coleccionismo.

\section{THE SANTA FAZ, A DEVOTIONAL IMAGE, IN THE CONVENTS OF TOLEDO}

\section{Abstract}

This research aims to spread knowledge about Toledo's abbeys Santa Faz s' diferent iconographies and pictorial styles. Works, occasionally, anonymous and unpublished. A comparative analysis has been developed between the di erent versions of this devotional image, from the sixteenth century s second term until the fourth decade of the seventeenth century.

Di erences between El Greco's mannerist iconographic model and two European baroque painters - Zurbarán, Philippe de Champaigne- as well the style and the technique of Madres Benitas Abbey s canvas are analyzed.

The inquiry done, through archives and literature sources, provides new data with regards to the relationship of the art collector Andres Passano de Haro, with Geneva; and supports the attribution of the Madres Benitas s Abbey Santa Faz s authorship to Rubbens or Van Dick.

\section{Keywords}

Veronica, iconography, mannerism, baroque, collecting 


\section{Introducción}

La representación del rostro de Cristo sobre un paño es fruto de una tradición que relata el evangelio apócrifo de Nicodemo. Camino del calvario, una piadosa mujer enjugó el ensangrentado rostro de Jesús con un paño plegado en tres dobleces, donde quedó impresa, en cada una de las superficies, el rostro del Salvador. Las primeras representaciones aparecieron, a partir del siglo XII, en medallas de estaño, y en los iconos rusos. "Vera imagen" dio lugar a la identificación de la mujer con el nombre de Verónica y, a partir de la mencionada centuria, a su representación en el arte cristiano portando el sagrado paño.

El paño, del que se conservan infinidad de copias tuvo mucha importancia en el siglo XV y se pintaron tablas y lienzos como una poderosa imagen de culto, empleada sobre todo en obras de devoción particular, para provocar la meditación piadosa sobre la muerte de Cristo. Es también en este momento cuando por verónicas se denominan las pinturas auténticas del rostro de Cristo, produciéndose un cambio en el concepto: de la mujer portadora de la imagen a la propia imagen.

Mucho más frecuentes que las representaciones del solo lienzo con la faz de Cristo, serán las del Santo Velo sujeto por la Verónica o por ángeles, y sobre todo formando parte de escenas como la Misa de San Gregorio, Cristo camino del Calvario, La Crucifixión, Cristo Patiens, Cristo Varón de Dolores y la Verónica entre santos ${ }^{11}$.

Sobre el paño se muestra en rígido frontalismo y con solemne seriedad el rostro de Cristo con el nimbo crucífero. Se prescinde de la verónica o de los ángeles como soporte; se elimina la escena del calvario. Sólo interesa el rostro del Salvador.

El tipo humano de Cristo en las representaciones de la Verónica y de la Santa Faz es generalmente un hombre mediterráneo, moreno, de ojos oscuros. Ante esta faz, el espectador se siente atraído por la imagen y motivado por la mirada de sufrimiento contenido y aceptado.

Otra variante del tema es la imagen del paño sostenido por ángeles, que aparece por primera vez en un grabado de 1513 de Alberto Durero y que será ampliamente repetido en la iconografía religiosa contrarreformista.

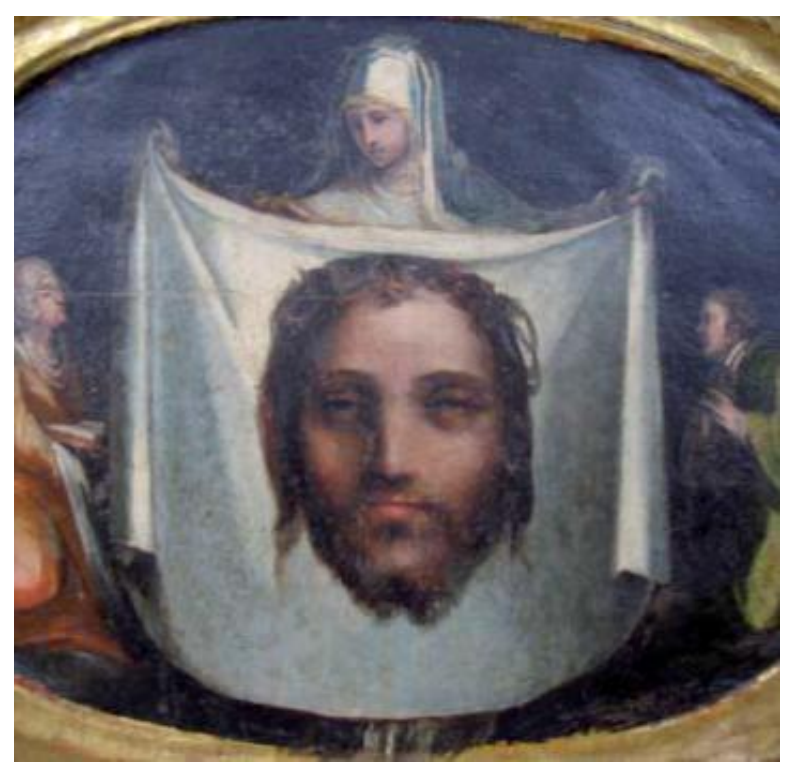

Fig. 1. Alonso de Berruguete, Santa Fa\%. h.1535.Retablo de la Visitación. Convento de Santa Úrsula. Toledo. Fotografía de Renate Takkenberg.

${ }^{1}$ AA.VV, 2006 


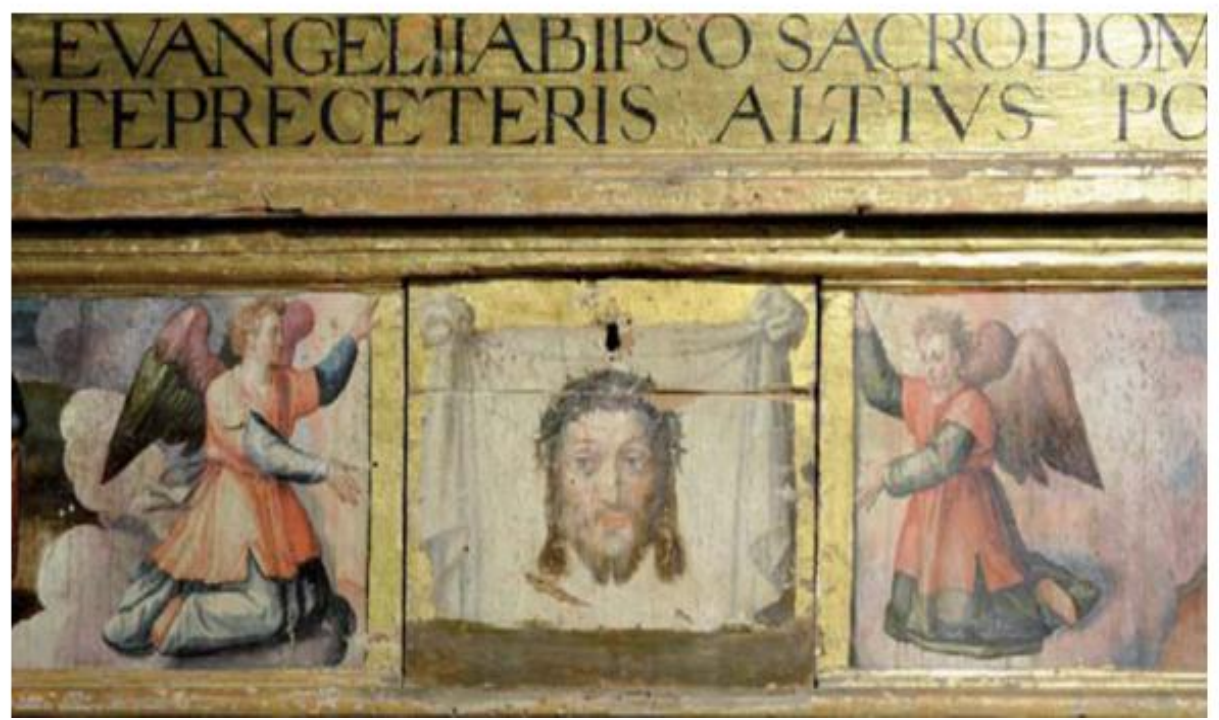

Fig. 2., Santa Faz. Retablo de San Juan Evangelista Convento de Santa Isabel de los Reyes. Toledo. Fotografía de Renate Takkenberg.

\section{Iconografía y estilo de la Santa Faz y Verónica en los conventos de Toledo}

En Toledo, ciudad conventual, a partir del siglo XVI cobra auge el tema de la Santa Faz. La imagen devocional surge como nueva forma de adoctrinamiento del fiel, más allá del púlpito y la teoría espiritual, primero en forma de estampas para trasladarse más tarde al lienzo. Cumpliendo con los preceptos de la "devotio moderna", el cuadro de devoción lograba el acercamiento y la empatía del devoto con la imagen representada, al prescindir de todo elemento disuasorio o accesorio. Colocado en oratorios privados de la demandante clase nobiliaria y de los conventos y congregaciones religiosas, su tamaño será necesariamente pequeño, por lo que habrá de condensar y potenciar el contenido emocional, tan adecuado para el desarrollo del culto y la oración.

Una Santa Faz muy original y de gran calidad (fig. 1) aparece en la predela del retablo de la Visitación en la Capilla de San Nicolás Tolentino del convento de Santa Úrsula, que esculpe y pinta Alonso de Berruguete hacia $1535^{2}$ En un encuadre oval, la Verónica sostiene el paño con una imagen de Cristo individualizada, aunque excesivamente frontal. La figura deja de ser un icono para convertirse en un Cristo humano. A ambos lados se representa a los donantes. El claroscuro y el color proporciona volumen y perspectiva: sobre un fondo azul oscuro adquieren volumen cromático los donantes, la dama en tonos anaranjados y el caballero en verdes, de raíz veneciana. El fondo se aclara hacia la parte de las cabezas de los donantes, de la Verónica y de la faz de Cristo, y adquiere un simbólico azul celestial.

En la Iglesia del convento de Santa Isabel de los Reyes, la Santa Faz está situada en el centro de la predela del retablo de San Juan Evangelista, obra anónima, de comienzos del XVII (fig. 2). Sobre fondo dorado, de tradición medieval, el rostro de Cristo grabado en paño de dos nudos, muestra un naturalismo barroco que se aleja de la imagen icónica tradicional, por su fisonomía de tez clara, ojos azules y cabellos y barba rubios. Dos ángeles a ambos lados de la tabla central, simulan sostener el paño, como en el grabado de Durero. Su

\footnotetext{
${ }^{2}$ Gómez Moreno lo sitúa en la década de los cuarenta y Azcárate , Gaya Nuño y Martínez Caviró en la segunda mitad de la década de los treinta
} 


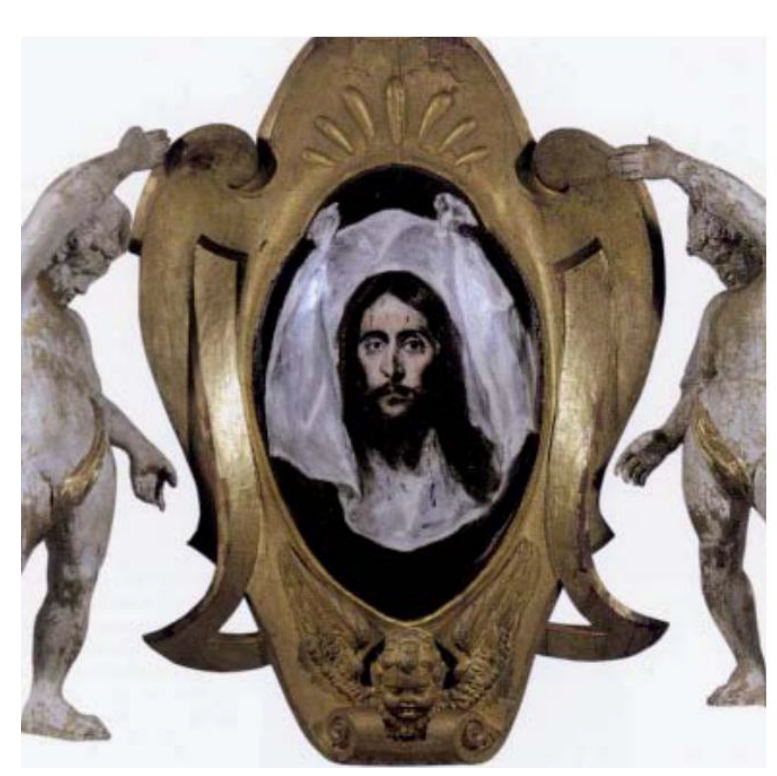

Fig.3. El Greco. Santa Faz. 1577-79 Santo Domingo el Antiguo. . Toledo. Fotografía de Renate Takkenberg.

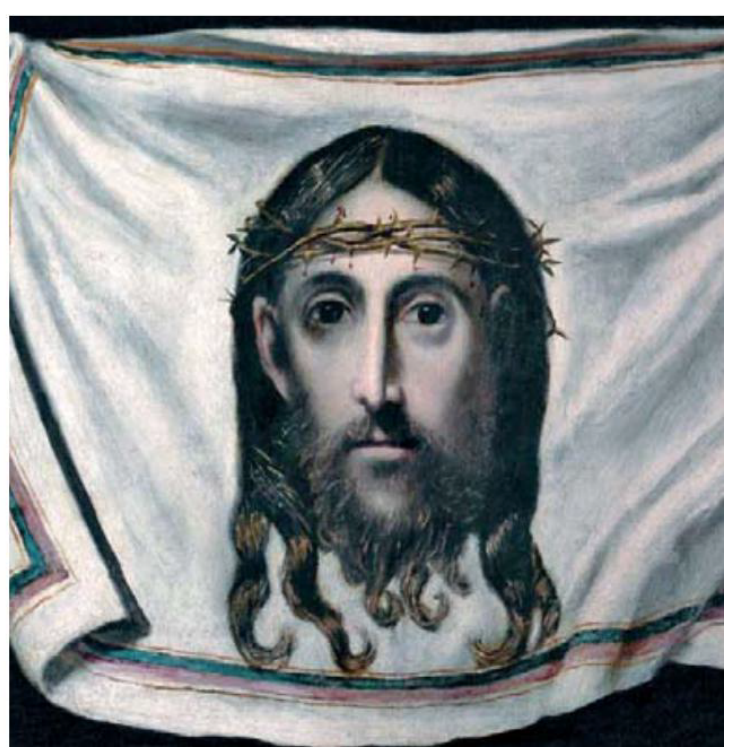

Fig. 4. El Greco. Santa Faz. Ha 1580 Conventto de la Purisima Concepcion (capuchinas). Toledo. Fotografía de Renate Takkenberg..

antecedente lo encontramos en el Mandylión de la cultura bizantina, que alcanzó gran arraigo en la escuela valenciana hasta mediados del siglo XVI.

Entre 1577 y 1580 Dominico Greco crea el modelo iconográfico de la Santa Faz manierista, de intensa espiritualidad. El solo rostro de Cristo estampado sobre el velo, con dos nudos en los ángulos superiores, sin ningún elemento de distracción, al convertir los ángeles en tenantes del marco, generalmente, portadores del lienzo: Verónica de Santo Domingo el Antiguo (fig. 3).

Este mismo modelo lo repitió para la Iglesia parroquial de Móstoles, hoy en el Museo del Prado, y con muy poca variación en las versiones de la Colección Goulandris y del convento de Capuchinas de Toledo (fig. 4).

En manos del candiota el tema de la Santa Faz cobra gran importancia, cambiando su tradicional ubicación, en el banco de los retablos, al ático de los mismos: retablo mayor de la Iglesia del convento de Santo Domingo el Antiguo y en el desaparecido retablo de la Iglesia de Santa Leocadia.

A principios del XVII, numerosos artistas sitúan, como el Greco, esta iconografía en el ático de los retablos: el anónimo artífice de la Santa Faz del retablo de la Ermita de San Jerónimo (fig. 5). La construcción se inicia en 1611 por el canónigo de la catedral Don Jerónimo de Miranda Vivero para dar culto a los moradores de los Cigarrales ${ }^{3}$. El retablo de traza barroca clasicista del primer tercio del XVII, alberga una imagen de San Jerónimo del siglo XX, copia de modelos anteriores, y una Santa Faz muy cercana a la que, en torno a 1610, pinta Diego de Aguilar el joven para el convento de San Clemente de Toledo (fig. 6). Ambas presentan similitudes en los anudados, plegados y sombreado del paño, en la posición y fisonomía del rostro, sereno, impasible, sin muestra alguna de dolor, y carecen de corona de espinas.

Isabel Mateo fundamenta la atribución a Aguilar el Joven, en la similitud del rostro de Cristo con el que aparece en el Bautismo de Cristo, del mismo convento. No se conocen más

\footnotetext{
3 Vaquero Fernández-Prieto, 1997.
} 
Fig. 5. Santa Faz. Ha 1612 Ermita de San Jerónimo. Toledo.Fotografía de Renate Takkenberg..

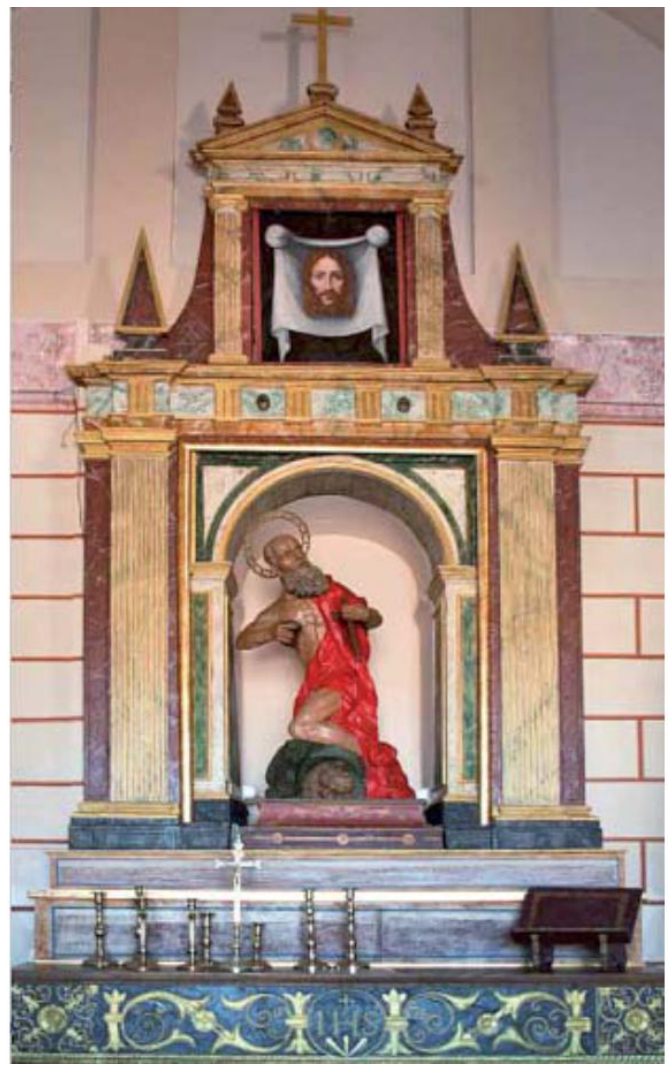

pinturas de este tema del pintor y desconocemos si formaría parte de un retablo, como la Santa Faz de la Ermita de San Jerónimo ${ }^{4}$. Una inscripción que no hemos podido leer en su totalidad y que ninguna publicación recoge, induce a pensar que se trata de un lienzo independiente realizado para un oratorio, como la tela de Santo Domingo el Real.

Características semejantes muestra el lienzo de este último convento. La barra que sujeta la tela y el nimbo trinitario son exactamente iguales que los que aparecen en la versión de San Clemente, pero la cabeza de Cristo se inclina dolorosamente hacia un lado y porta, además de una hiriente corona de espinas, la maroma al cuello, remitiéndonos a la iconografía del Ecce Homo (fig. 7). En la parte inferior del lienzo leemos la inscripción:"'SI LO MAS YZE POR TI Q FUE MORIR POR SALBARTE POR Q NO E DE PERDONARTE”. Se trata de una imagen devocional, cercana al orante, independiente de la narración de un retablo. La inscripción acentúa la proximidad, la finalidad doctrinal y la carga emotiva.

El Greco, al añadir al velo la imagen de la portadora, crea una de las iconografías más afortunadas dentro de su temprana producción: Verónica de la antigua Colección Caturla y Verónica del Museo de Santa Cruz de Toledo (fig. 8).

La Verónica, suele representarse como una mujer joven, con la cabeza velada, sujetando el lienzo en diversas posiciones. Una particular representación de la mujer se exhibe en el convento de San Pablo, transmutada en un ser angelical de alas desplegadas, ornada con un bello pectoral perlado y una corona floral; el consabido paño deja paso a una ampulosa tela que las manos del ángel arruga para poder sujetar (fig. 9). Obra anónima y creemos que inédita, de buena calidad pero deteriorada, carente de movimiento pero con rostro humanizado y mirada reflexiva.

${ }^{4}$ Mateo /López-Yarto, 2003: 33. 


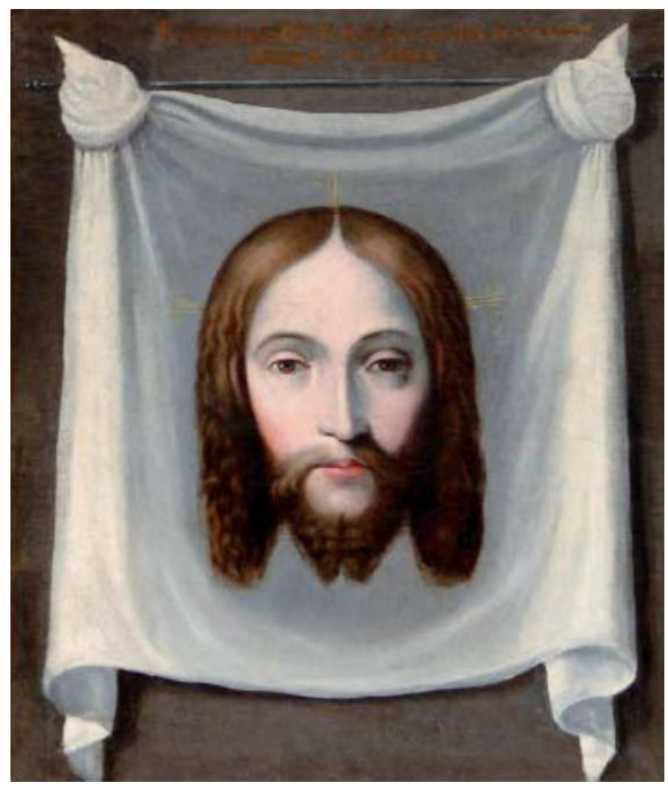

Fig. 6. Diego de Aguilar el JovenSanta Faz. Ha 1610 Convento de San Clemente.. Toledo. Fotografía de Renate Takkenberg.

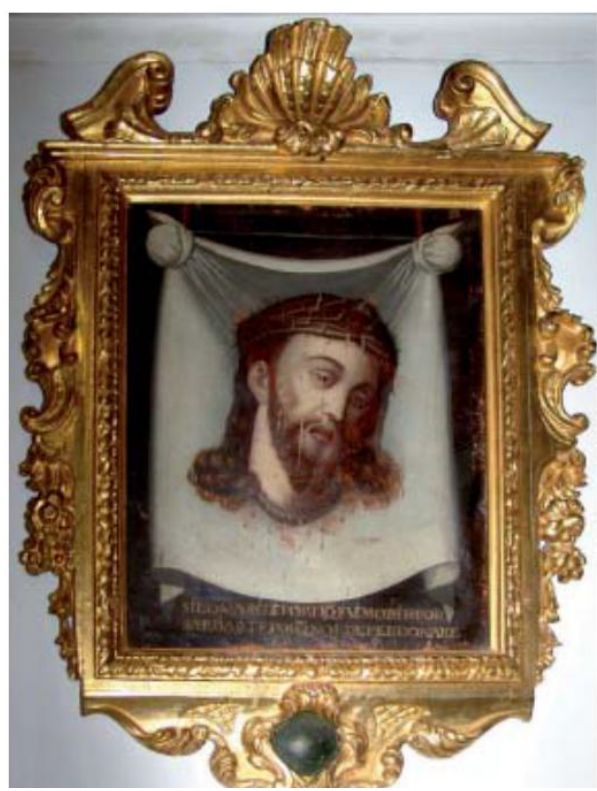

Fig. 7. Santa Faz. Convento de Santo Domingo el Real. Toledo. Fotografía de Renate Takkenberg..

La cara de Cristo aislada se difundirá particularmente en el barroco, por lo general, con la cabeza coronada de espinas, uno de los elementos simbólicos, quizás el más significativo, del conjunto de Arma Christi que se había popularizado en el gótico.

Zurbarán pintó diversos óleos sobre lienzo, algunos firmados y fechados, el Catálogo de Gudiol recoge diez versiones consideradas autógrafas. El más antiguo, de 1631, y el más tardío de $1658^{5}$. Presenta la tela sujeta con alfileres y con nudos pequeños en los ángulos superiores, de modo que el rostro queda enmarcado por pliegues de forma triangular alusión simbólica de la Trinidad-. La Santa Faz de la Parroquia de San Pedro de Sevilla de hacia 1640, muestra gran plasticidad y naturalismo, característicos del barroco, pero la fisonomía de Cristo sigue siendo mediterránea (fig. 10).

En Francia, donde existía una gran devoción hacia la corona de Cristo, que San Luis había llevado procedente de Tierra Santa, Claude Mellan, pintor y grabador que realizó fundamentalmente grabados religiosos y retratos, muestra en su Santa Faz de 1649, estampa a buril (43 X $22 \mathrm{~cm}$ ), un tipo iconográfico que tuvo una gran aceptación: rostro individualizado y verista expresión de dolor, pero mantiene la posición frontal (fig. 11).

\section{La Santa Faz del Convento de Madres Benitas de Toledo}

En la clausura del convento, sobre la puerta de ingreso al coro, se conserva una Santa Faz singular tanto por la calidad pictórica que presenta como por la originalidad iconográfica ${ }^{6}$ (fig. 12). Los investigadores que se han ocupado del patrimonio artístico de este convento, Martínez Caviró y Suárez Quevedo, sólo nos informaban de una Santa Faz legada, junto con otras obras artísticas, por Andrea Passano de Haro, sin ofrecer ningún dato más.

Desde el punto de vista técnico la obra evidencia la mano de un excelente pintor del Barroco influido por los grandes maestros venecianos del XVI, especialmente por el colorido de Tiziano, por lo que, llevando a cabo un estudio comparativo de diversos aspectos de esta

\footnotetext{
${ }^{5}$ Gállego/Gudiol, 1999: 122-123

${ }^{6}$ Anguiano de Miguel/ Fernández, 2012:153-167
} 


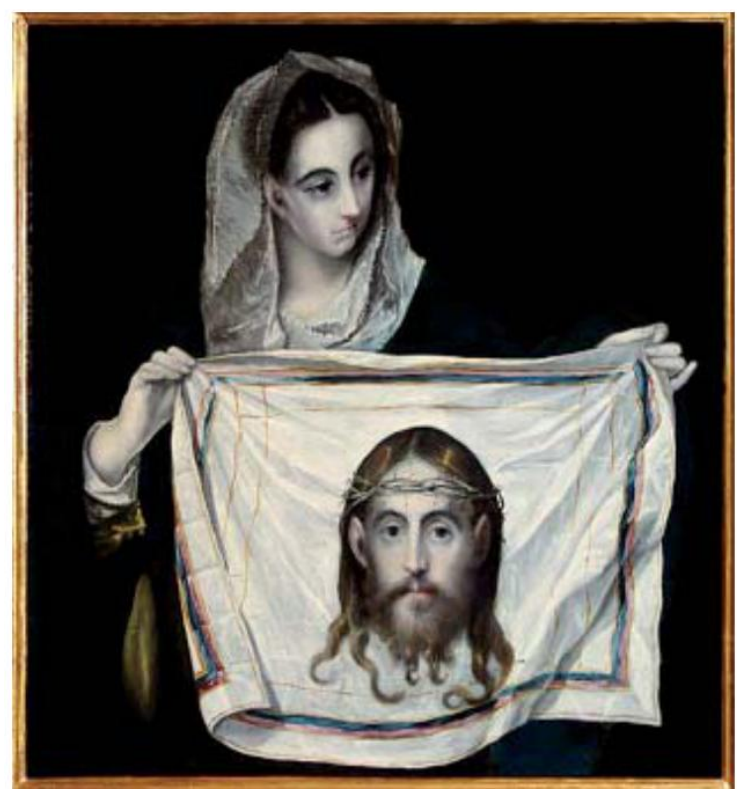

Fig. 8. El Greco, La Verónica. Ca.1580. Museo de Santa Cruz. Toledo. Fotografía de Renate Takkenberg.

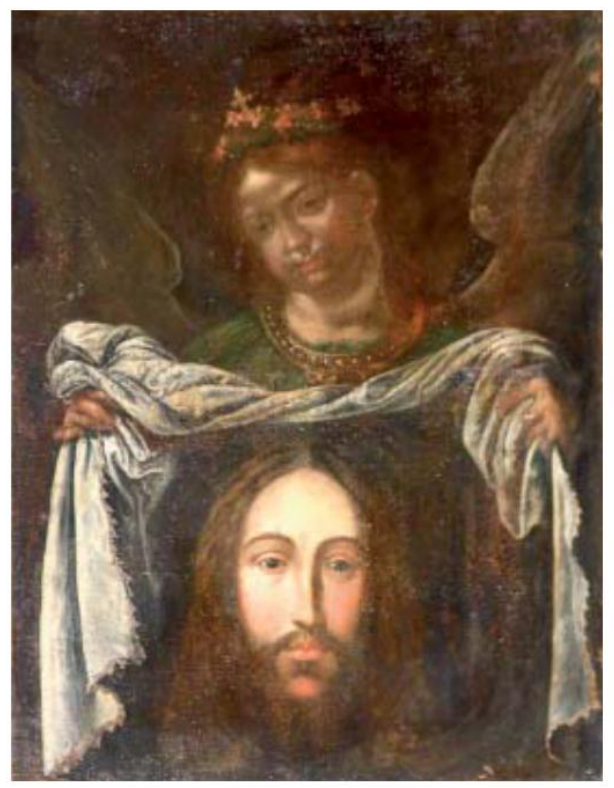

Fig. 9. La Verónica Convento de San Pablo.. Toledo. Fotografía de Renate Takkenberg..

pintura con obras de Rubens y con otros pintores barrocos nos inclinamos a pensar pudiera tratarse de una obra de este entorno.

Rubens, durante su estancia italiana (1600-1608), estuvo pocos meses en Génova, pocos días al inicio de 1604, quizás al final de 1605 o en 1606 y con seguridad en el verano de 1607, pero la relación con los clientes y coleccionistas de la ciudad duró mucho más?.

La iconografía de la iglesia de los Jesuitas en Génova se inicia en torno a 1605 con la colocación en el altar mayor del lienzo de Rubens de la Crucifixión, obra encargada al maestro flamenco por Niccolo Pallavicini, hermano del fundador y promotor de la iglesia, el padre Marcello.

Rubens había italianizado su modo de pintar por influjo de la pintura veneciana del XVI -Tiziano, Tintoretto y Veronés-, conocidos en las colecciones de Mantua, y adoptará una pincelada rápida y rica de materia. Supo fusionar diversos logros de distintos maestros italianos y conformar un nuevo estilo marcadamente personal y reconocible. Un estilo exuberante y colorista, de pinceladas muy sueltas, que se inspira en modelos reales para representar los pasajes sagrados con el lenguaje de lo verosímil y tangible. A su vez, por influjo del maestro flamenco y de su discípulo Van Dyck, los pintores genoveses cambian la tendencia toscana-romana del dibujo por la del color veneciano.

La uniformidad estilística y técnica de Rubens (1577-1640) y Van Dyck (1599-1641), su joven y mejor discípulo, cercano al maestro en el modo de entender el color como estructura y colaborador de numerosas obras, dificulta la atribución de algunas pinturas. En 1617 trabaja en el taller de Rubens y copia las pinturas del maestro para que sirvan de modelo a los grabados; en 1618 figura inscrito como maestro en la Guilda de San Lucas. De un pleito a propósito de la serie del Apostolado, se deduce que a partir de esa fecha cuenta con un taller propio en Amberes con ayudantes, pero sigue colaborando con Rubens, en los techos de la iglesia de los jesuitas de Amberes (1620); y en Venus y Adonis, hacia 1620, retrata a Rubens

\footnotetext{
${ }^{7}$ Boccardo/ Orlando, 2004: 23
} 


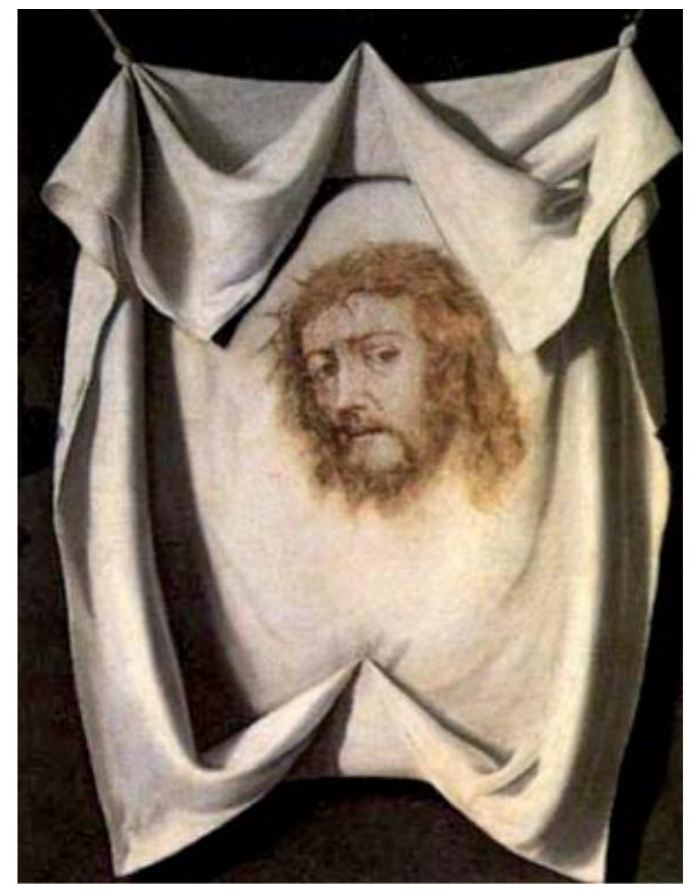

Fig. 10. Zurbarán, Santa Faz: Parroquia de San Pedro. Sevilla

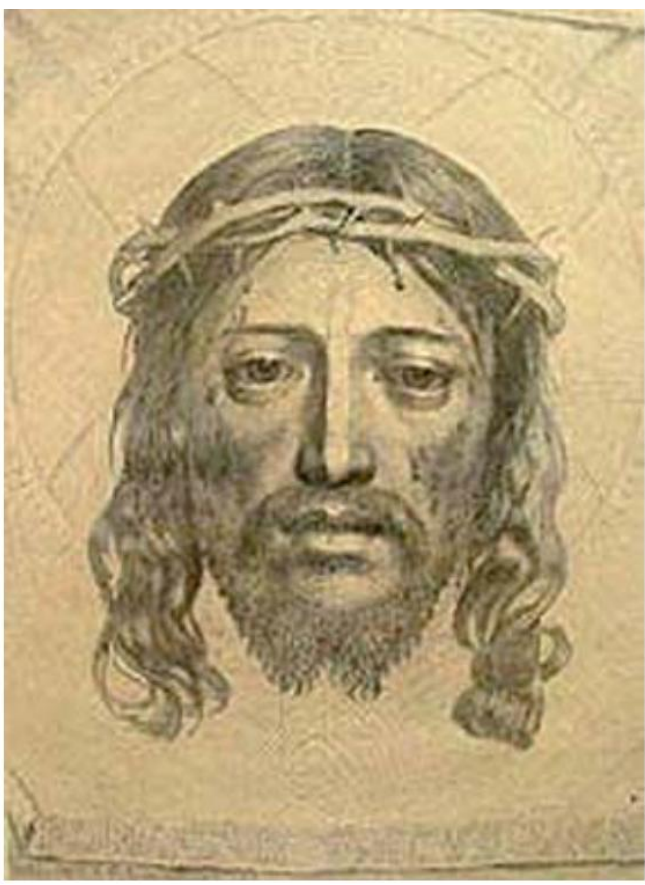

Fig. 11. Claude Mellan. Santa Faz. 1649. (45x22cm) Biblioteca Nacional de Madrid.

en el rostro de Adonis. Los autorretratos de Van Dyck muestran una fisonomía flamenca similar a la Santa Faz de las Benitas.

La Santa Faz $(60$ X $66 \mathrm{~cm}$.) de la colección Passano presenta novedades respecto a la iconografía tradicional, que responde a ideales de la contrarreforma humanista y refleja el espíritu devoto de la época, exaltando la Eucaristía, la Virgen, los santos y las reliquias, frente a la doctrina protestante.

El rostro es de un hombre del norte de Europa, de tez y ojos claros, cabellos castañosrojizos y rasgos fisionómicos constantes en los autorretratos de Rubens: boca carnosa con pequeño surco c entral en el labio inferior, bigote largo y con doble curva y perilla, nariz recta y larga con ternilla realzada por una pincelada luminosa, ojos de párpados marcados con leve sombreado que define también las ojeras y cejas de trazo curvo (fig. 13). En los autorretratos dirige la mirada al espectador y en el rostro de Cristo al Padre Eterno, en una actitud característica de la pintura e imaginería barrocas y rubenianas. El Martirio de San Andrés, del pintor flamenco, dirige su mirada a Dios Padre, así como el San Sebastián de Carreño (1656) o San Francisco en el Éxtasis pintado por Ribera (1642); y en la imagen del mismo santo, obra de Pedro de Mena (1663), por citar algún ejemplo.

El pintor flamenco acostumbraba repetir modelos y repintar lienzos ya terminados, ha sido un gran retratista y ha utilizado modelos del natural de su entorno familiar. Conocemos su fisonomía a través de autorretratos y retratos insertos en composiciones religiosas y profanas, ejecutados por el mismo y de numerosas copias que presentan un rostro semejante a la Santa Faz de las Benitas.

El retrato más antiguo conocido del pintor es Autorretrato con sus amigos de Mantua. Museo Wallraf Richartg, Colonia, c.1602 (fig. 14), donde retrata por vez primera, entre otros tres personajes masculinos, al filósofo Juste Lipse y a su hermano Felipe ${ }^{8}$. El pintor, en primer

8 Sobre esta pintura puede consultarse Rubens a Mantova. Mantova, palacio ducale 25 settembre / 20 novembre 1977. Milano, Electa editrice, 1977; y en Rubens. Lille, Palais des Beaux-Arts, 6 mars -14 juin 2004. París, Étitions de la Réunion des musées nationaux, 2004 


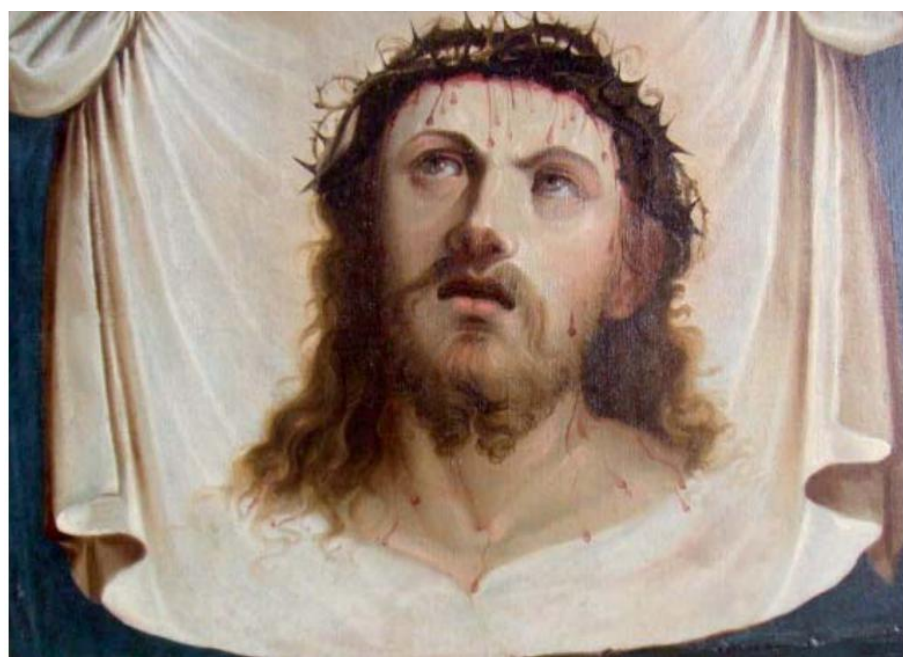

Fig. 12. Santa Faz. Convento MM Benitas, Toledo. Fotografía de Renate Takkenberg

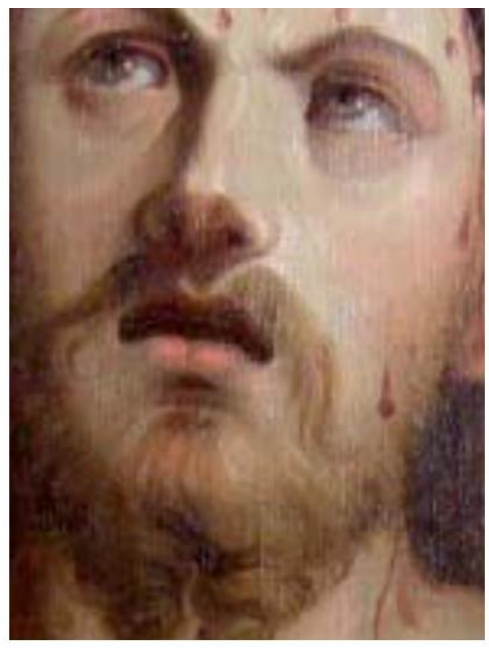

Fig. 13. Por menor. Santa Faz: Convento MM Benitas, Toledo. Fotografía de Renate Takkenberg.

plano, dirige la mirada al espectador reclamando su atención. Es la figura mejor definida que muestra el influjo de los maestros venecianos: técnica de toques de pincel para marcar la perilla y el bigote similar a la Santa Faz.

Se ignora el orígen de la pintura Los cuatro filosofos, conocido también como Juste Lipse y sus discípulos, óleo sobre tabla 164 X $139 \mathrm{~cm}$, (fig. 15), realizada en torno a 1611-1614, pero a fines del XVII se encontraba en el Palacio Pitti. Dedicada a su hermano mayor Felipe (1574-1611), humanista y discípulo de Justius Lipse y al filósofo de la Universidad de Lovaina, muerto en 1606, rodeado de sus discípulos: Jan Woverius, Felipe con la pluma en la mano, y Rubens. Los tulipanes a la izquierda del busto de Séneca aluden al homenaje de los dos personajes vivos a los fallecidos, como han sugerido diversos especialistas ${ }^{9}$. La pintura refleja la estrecha relación intelectual y espiritual entre los personajes, y testimonia la formación humanística de los hermanos Rubens. Tanto la fisonomía del pintor como la de su hermano recuerdan la de la Santa Faz que analizamos, por lo que se podría pensar que el lienzo fuera una alegoría de la muerte de su hermano, fallecido en la plenitud de la vida como Jesucristo. El Retrato de Felipe, óleo sobre tabla, 68,5 X 54, The Detroit Institut of Arts, realizado por el Fig. 17. Autorretrato con gran sombrero, 1623-25. pintor para el monumento funerario de su hermano en la abadía de San Miguel de Amberes, es semejante al rostro de las Benitas ${ }^{10}$ (fig. 16).

El Autorretrato con gran sombrero, óleo sobre tabla $(58$ x $61 \mathrm{~cm}$.), pintado entre 1623 y 1625 , cuyo original se halla en Windsor Castle, del que existen diversas copias, entre ellas la de Florencia, muestra la misma fisonomía (fig. 17).

Philippe de Champaigne (1602-1674), heredero de la tradición flamenca e impregnado de una profunda espiritualidad, trata el tema de la Santa Faz de manera clásica y realista como Rubens. En la exposición del Museo Rath (2007-2008), del pintor belga, activo en París desde 1621, se mostraban dos Santa Faz, una de hacia 1630 inspirada en un grabado de Lucas Vosrsterman, Biblioteca Nacional de Francia y otra de 1658, de Royal Pavillon de Brighton ${ }^{11}$ de excelente calidad y penetración psicológica, como el cuadro de las Benitas: paño con dos

9 Bodart, 1981: 44-45.

${ }^{10} \mathrm{El}$ grabado realizado de este retrato por Cornelis I Galle, publicado en 1615 confirma que se trata del hermano de Rubens. Véase Rubens, Catálogo Exposición Lille, Op. Cit.p.127

11 Philippe de Champaigne 1602-1674. Entre politique et dévotion. Catálogo exposición. Palais des BeauxArts, Lille/Musée Rath..Genève, 20 septembre 2007 - 13 janvier 2008, pp. 200-201. 


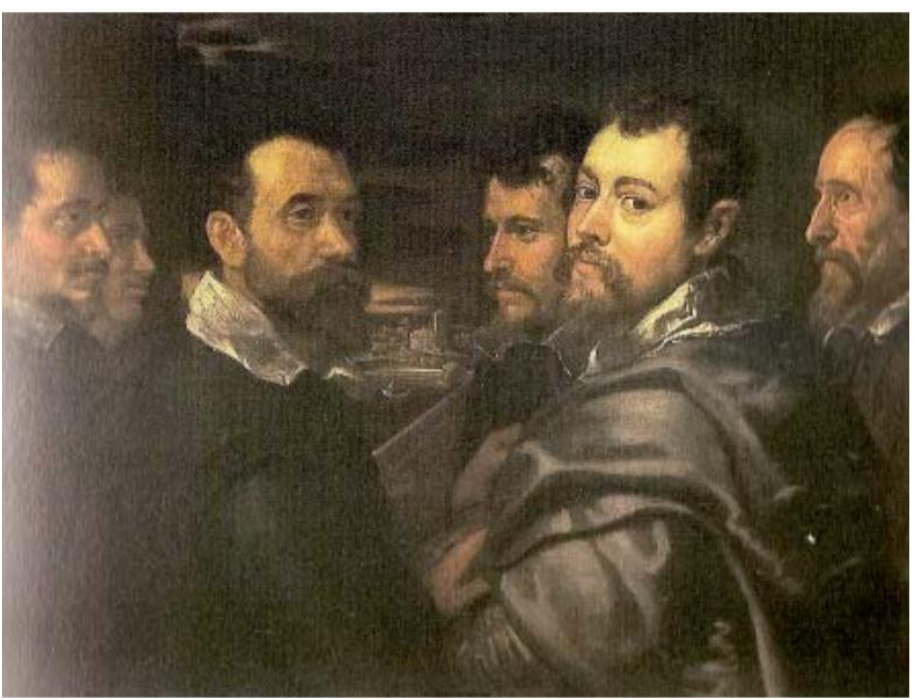

Fig. 14. Autorretrato con sus amigos de Mantua., Museo Wallraf- Richartg, Colonia, c. 1602

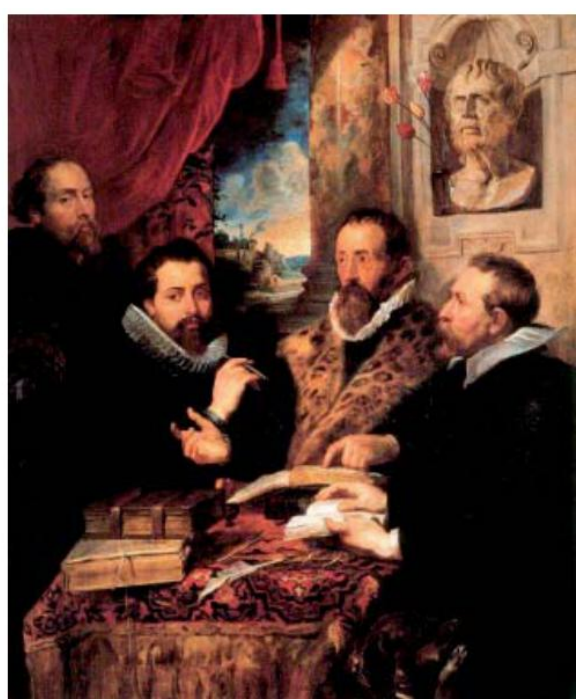

Fig. 15. Justo Lipse y sus discipulos. 'Los cuatro filósofos". c. 1611-1614. Palacio Pitti, Florencia

nudos, aunque uno de ellos se halle tapado por el cortinaje verde, de gusto barroco. Tanto por presentar la imagen de Cristo con la corona de espinas como por el naturalismo y colorido de la sangre que gotea por el divino rostro, se asemeja a la imagen que atribuimos a Rubens, aunque difiere de ella en la frontalidad del rostro de tradición medieval y en la fisonomía mediterránea (fig. 18).

La manera contenida y el color monócromo y frío Champaigne y de Zurbarán, difieren del colorido exuberante y la expresividad de la pincelada de la Santa Faz del convento de Madres Benitas.

El Cristo de la colección Passano no mira al espectador como es usual, sino a Dios Padre, de forma semejante a los martirios y apoteosis de Santos de Rubens: Tríptico de la Erección de la Cruz (1610), catedral de Nuestra Señora de Amberes; los Milagros de San Ignacio de Loyola, para la Iglesia de los Jesuitas de Amberes; la Asunción de la Virgen (H. 1614), del Museo de Bellas Artes de Bruselas, entre otras pinturas. El lienzo toledano por su iconografía, naturalismo, técnica barroca y por la coincidencia con las pinturas de la estancia de Rubens en Italia, nos inclina a datarla entre 1611, año de la muerte de su hermano Felipe, y 1620.

La estancia de Rubens en Génova, y su vinculación con el arte italiano y especialmente genovés, perduró en él hasta el punto de que incluso la casa que se manda construir en Amberes refleja la fusión de elementos arquitectónicos de los palacios manieristas genoveses y soluciones del hábitat flamenco.

Muy distante en calidad técnica y en mal estado de conservación, la Santa Faz del convento de Santa Úrsula, pintura anónima, es el único ejemplo que, desde el punto de vista iconográfico, se asemeja a la Santa Faz del convento de Madres Benitas, que podría haber sido su fuente de inspiración. Cabeza inclinada hacia el lado izquierdo y mirada al Padre. Gesto doliente y la boca entreabierta, sin rastro alguno de sangre en el rostro ni en el cuello y, sobre todo, carente del naturalismo y expresividad. (fig. 19).

\section{La técnica de Rubens}

A partir del siglo XVII con el arte barroco los pintores eligieron como soporte favorito de sus pinturas el óleo sobre lienzo, siendo éste más práctico para la elaboración de grandes composiciones que la tabla. Los pintores barrocos se caracterizaban por ser directos en grado extremo (capas con gran vitalidad y mínimas correcciones). Rubens utiliza una imprimación oscura o neutra y emplea diferentes tipos y clases de lienzos. A penas se encuentran barnices 


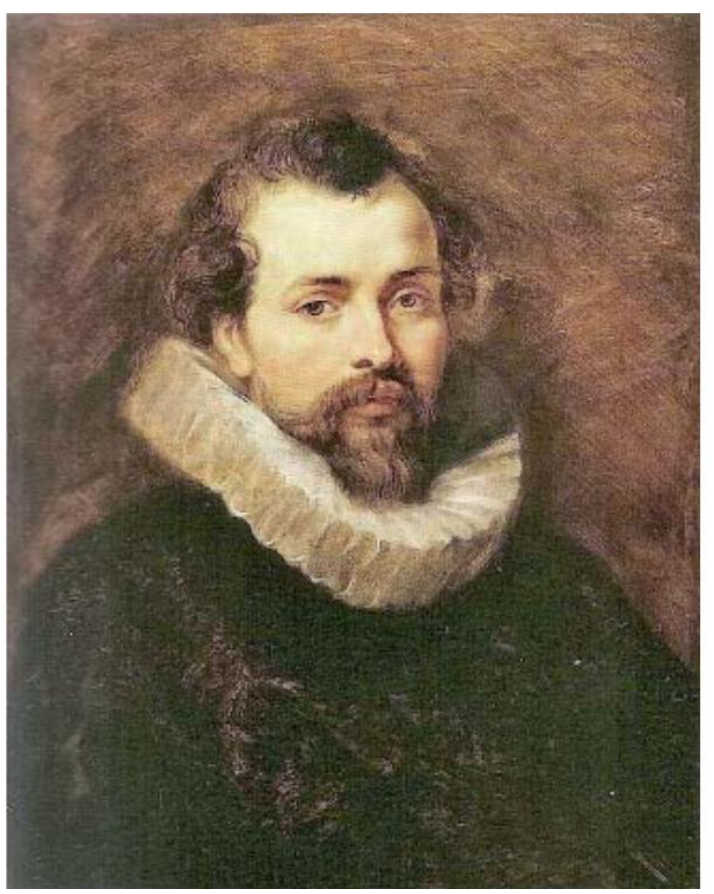

Fig. 16. Retrato de Felipe. Óleo sobre tabla $(68,5 \times 54 \mathrm{~cm})$ The Detroit Institut of Arts

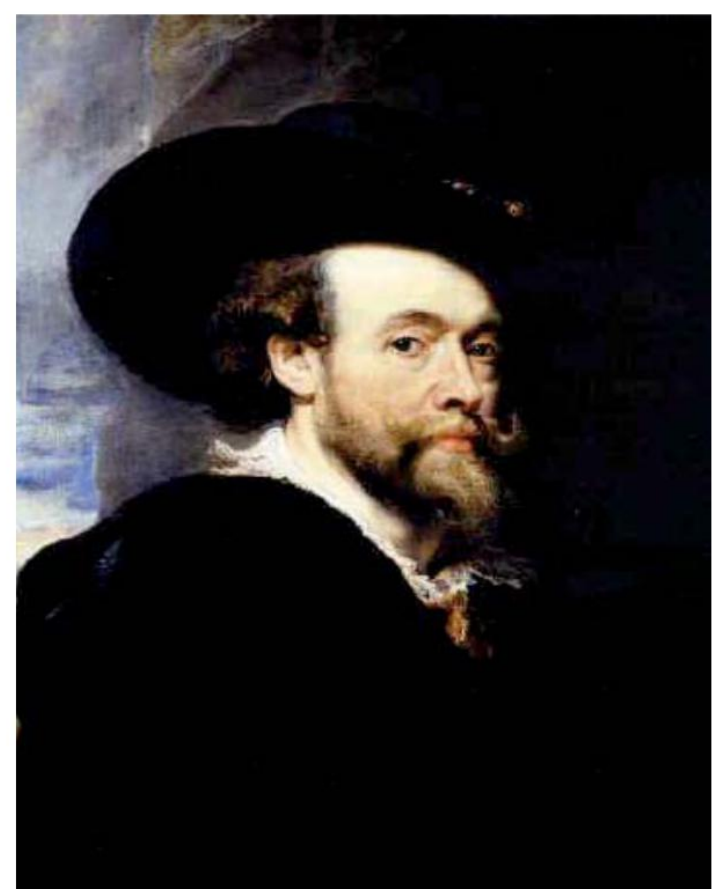

Fig. 17. Autorretrato con gran sombrero, $1623-25$

originales en su pintura. Debido al perfecto trabajo previo y a la de resistencia de sus pigmentos, no necesitaba aplicar el barniz en capas gruesas, empleando barnices volátiles y de secado rápido y retoque en las aplicaciones de veladuras e intermedias ${ }^{12}$.

La magnitud de la producción de Rubens, en número, dimensiones y calidad, demandaba una combinación de capacidad, rapidez y destreza y la participación de sus numerosos ayudantes.

En el siglo XVII ya era común encontrar "imprimaturas" (capas coloreadas) sobre la base de preparación blanca. Comparada con la técnica pictórica del siglo XV, la utilizada por Rubens es muy simple: las sombras se obtienen en un mínimo espesor, con una sola capa oscura aplicada sobre una "imprimatura" gris. En cuanto a los blancos, no presentaban ningún problema para Rubens puesto que a él le gustaban opacos y esta opacidad oculta totalmente el fondo, sea éste gris o de otro color. Sobre la base de un fondo oscuro, se llega a sombras delgadas pero se está obligado a empastar para obtener los valores claros. Su técnica evoluciona hacia una mayor simplicidad — con capa pictórica generalmente únicapermitiendo mayor rapidez de ejecución.

En sus bocetos, realizados sobre paneles de madera, colocaba, encima de la preparación blanca, una delgada capa de imprimatura gris o marrón que por regla general no era uniforme sino rayada; siendo ésta un elemento tan constante en sus bocetos, que su ausencia podría ser una señal de atención al hacer atribuciones de su obra.

Fusionó el método de los venecianos con el de los flamencos, uniendo sombras transparentes con luces empastadas, aplicando una técnica que permitía una pintura rápida: las sombras las diluía con barniz, y las luces con empastes densos ${ }^{13}$.

La Santa Faz de las Benitas, antes de la restauración presentaba un tono amarillento derivado del envejecimiento de la resina natural de almáciga utilizada por Rubens en sus barnices y el lino de hilos irregulares, característicos de su fabricación manual, del mismo

12 Doerner, 2001: 332-335

13 Álvarez, 2009 


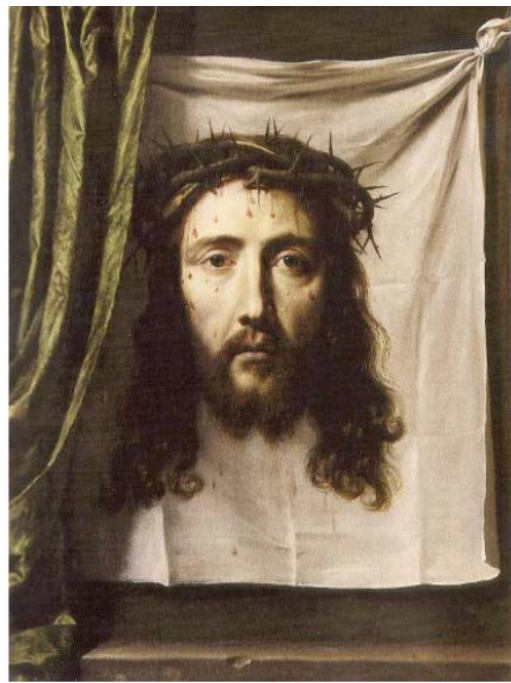

Fig. 18. Philippe de Champaigne Santa Faz. 1658. Royal Pavillon de Brighton

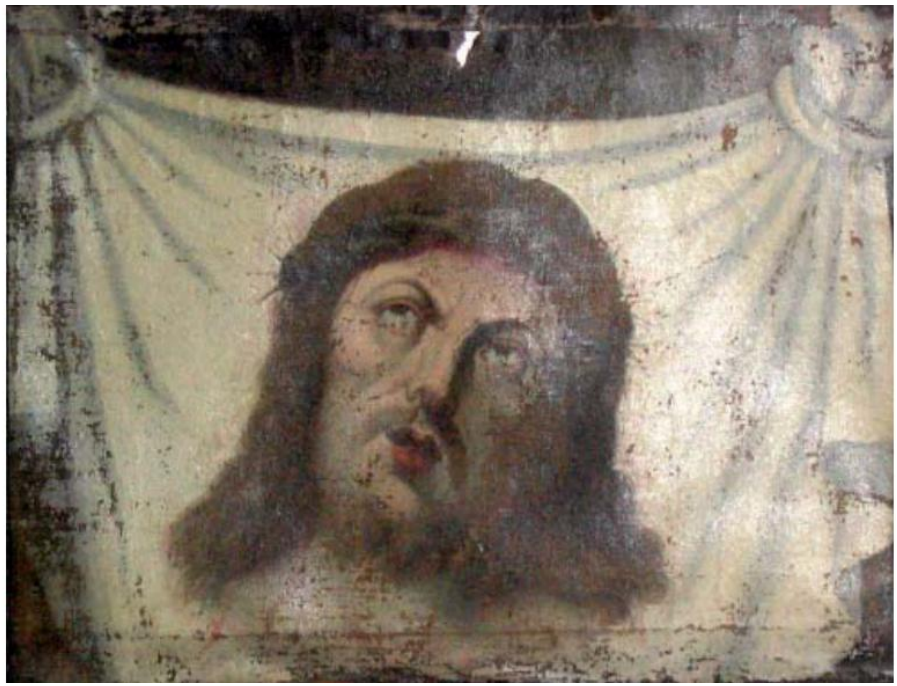

Fig. 19. Santa Far. Convento de Santa Úrsula. Toledo. Fotografía de Renate Takkenberg.

modo que en la Adoración de los Magos, del Museo del Prado, recientemente restaurada ${ }^{14}$ (fig. 20).

\section{El coleccionista Andrés Passano de Haro}

La documentación del Archivo de la catedral de Toledo vincula a Andrés Passano de Haro con los artistas genoveses contratados por don Álvaro de Bazán, marqués de Santa Cruz, para construir y decorar su palacio en el Viso del Marqués (Ciudad Real).

El capellán de la Capilla de los Reyes Nuevos nacido en 1629, era hijo de Pedro María Passano natural del Viso y de Mariana Orozco, natural de Madrid. Sus abuelos paternos fueron D. Juan María Passano, natural de Framura, lugar a ocho leguas de Génova, del cual han sido señores los de este apellido y doña María Lorencio, natural de El Viso, y los maternos, D. Juan de Haro y doña Ana de Orozco, ambos naturales de Madrid ${ }^{15}$.

En el Archivo del Viso del Marqués aparece contratado desde 1570 Alberto Passano, maestro de mayor de carpintería ${ }^{16}$ Juan Bautista Casella albañil se casa con Jerónima Passano" 1589 (12-9): "desposé a Juan Bautista alvañil y a Jeronima pasana fueron padrinos Anton Franco y m su mujer Testigo Fco... y me Cesar" (fol. 3v) ${ }^{17}$.

Un Bartolomeo Passano, pintor, discípulo de Giovanni Battista Carlone, activo en Génova en el XVII, pintó el atrio de la Iglesia de Santa Marta y la Scala ${ }^{18}$.

La colección de Passano refleja la ideología y gusto artístico de un clérigo culto de la Contrarreforma católica, predominando el arte sacro barroco español. El tema de la Santa Faz como objeto artístico al servicio de la devoción cristiana se adecúa a su personalidad.

La Santa Faz de esta colección difiere del modelo toledano, tanto de la Santa Faz retardataria del convento de San Clemente, obra de Diego de Aguilar, de la de Alonso Berruguete, como de la innovadora de El Greco y de todas las pinturas que hemos

\footnotetext{
14 Garrido/ García Maiquet, 2004: 142.

15 Archivo de la catedral de Toledo. Índice de Capellanes de la Capilla de Reyes Nuevos

16 López, 2004: 132.

${ }^{17}$ Archivo Parroquial de El Viso. Libro de las personas que se han desposado y velado en la villa del Viso desde el año 1586 (15-1) a 11-2-1619 (12-9). En López, 2007.

18 Soprani/ Ratti, 1969: 9
} 


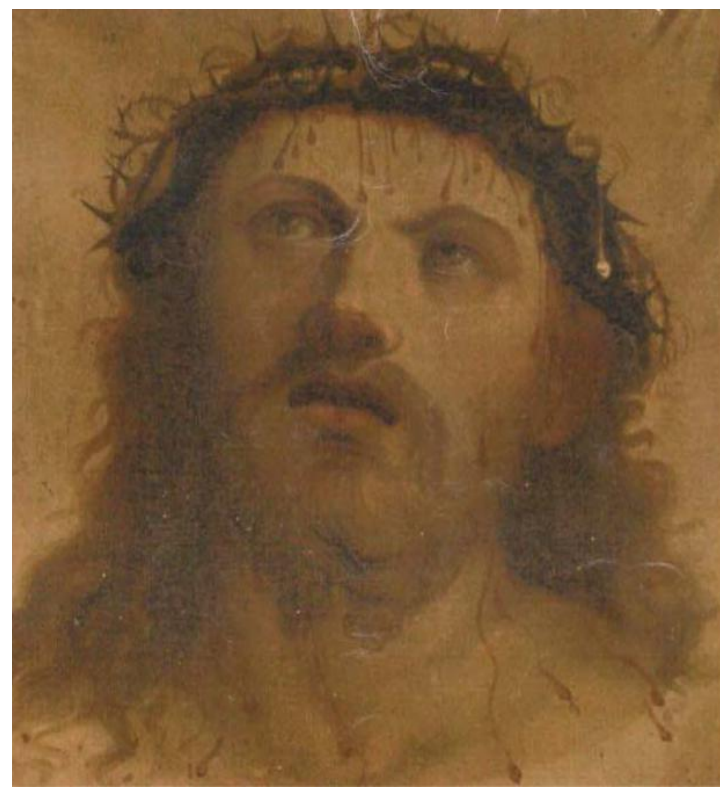

Fig. 20. Santa Faz. Convento MM Benitas, antes de la restauración.

investigado. ¿Heredó Passano la Santa Faz que atribuímos a Rubens de su abuelo paterno? ¿Compró al mercader flamenco Juan de Briones esta Santa Faz rubeniana?

El linaje de Haro en el siglo XVII proporciona personajes poderosos en la política, que son también grandes coleccionistas. Don Gaspar de Haro y Guzmán, IV marqués del Carpio y marqués de Heliche, virrey de Nápoles entre 1683 y 1687, se cuenta entre los coleccionistas españoles más importantes de todos los tiempos. En la Antigua colección del marqués (1689) estaba La Coronación de Espinas, obra de Van Dyck, de dimensiones desconocidas. Según Díaz Padrón no conviene vincularla con ninguna de las versiones conocidas ${ }^{19}$. Lamentamos no poder comparar esta pintura con el lienzo de la colección Passano.

Luis Méndez de Haro, sobrino y sucesor del Conde Duque de Olivares y ministro de Felipe IV, incrementó su colección con los cartones del Triunfo de la Eucaristía de Rubens, que el rey le regaló y que después donó al convento de la Inmaculada Concepción de Loeches, fundado por el conde en 1640, junto a su palacio, y terminado por su sobrino.

Andrés Passano, escritor y coleccionista hace testamento en Toledo el 4 de septiembre de 1687 a favor del convento de las Benitas del que era mayordomo: "dejó toda su hacienda a las religiosas", murió en Toledo el 25 de Diciembre de 1687 y "enterróse en el convento de las Benitas de esta ciudad, debajo del Altar de San Benito". Capellán de la Capilla de los Reyes Nuevos de la Catedral de Toledo desde el 15 de Abril de 1663, consultor del Santo Oficio y Secretario y confidente del Cardenal Baltasar Moscoso y Sandoval, con cuyas noticias sacó a la luz su vida con título "Deberes de Prelados". "Fue único en manejar los papeles de la real capilla, como manifiestan tanto trabajos suyos" (Relación nominal y datos biográficos así como fechas de posesión de los Sres Capellanes que han sido en la Real capilla de Reyes Nuevos de Toledo. (Años 1535 a 1976) ${ }^{20}$.

En el testamento de Passano se citan dos lienzos de la Santa Faz, uno de los cuales se trata sin duda del que atribuimos a Rubens, y toda una relación de obras religiosas, algunas de gran calidad, como una Virgen "vestida de gitana", iconográficamente relacionada con la Divina Pastora; una talla de la Inmaculada, de mediados del siglo XVII, con querubines, aureola de rayos, manos juntas y actitud simétrica al modo de Gregorio Fernández, parecida a las imágenes de la Soledad de la primera mitad del XVII, atribuida a Pedro de Mena por Juan Nicolau; un lienzo de Ecce Homo sentado, cuyo marco lleva la inscripción: "En la cruz

${ }^{19}$ Díaz, 2012: 743

${ }^{20}$ Hidalgo, 1670. 
está mi luz": SEDEVIT SOLITARIUS / ET TECEBIT QUIA/ LEVAVIT SE / SVPRASE; cabezas del Salvador y María sobre tabla; un cuadro de San Nicolás de Bari; un lienzo de religiosa muerta con manto azul, coronada de rosas, "Madre Sor María de Jesús María" fundadora de las madres de San Benito de Nuestra señora de la Concepción, que murió de 76 años el 16 de junio de 1665; un sacerdote, con casulla roja y cáliz en la mano; un Divino sembrador; una Virgen de Trápani, en alabastro policromado, copia barroca del original, en vez del siglo XIV como creyó Martínez Caviró; ocho pinturas de Juan de Toledo, cuatro marinas y cuatro de batallas, seis de ellas de vara y media y dos más pequeñas ${ }^{21}$.

Según la Comunidad de Madres Benitas, un Crucifijo de marfil, sobre cruz y peana de concha, pertenecía también a Passano; un taquillón de nogal, con incrustaciones de marfil y hueso, tal vez legado por el mismo, etc.

La atribución de la Santa Faz de las Benitas a Rubens, se apoya en el estilo y técnica barrocas creadas por el pintor en Italia, y en la vinculación de esta pintura con la muerte de su hermano mayor Felipe. La personalidad y la relación de Andrea Passano con artistas genoveses y coleccionistas españoles fundamentan la atribución a Rubens o Van Dyck.

Conscientes que el estudio, conservación y protección del Patrimonio Artístico se ha de afrontar de manera interdisciplinar, hemos tenido en cuenta las observaciones que nos ha comunicado la restauradora Marina Torres sobre el lienzo utilizado, el pigmento, etc., pero pensamos que las nuevas tecnologías de restauración, podrán arrojar luz sobre la autoría.

${ }^{21}$ Archivo Madres Benitas de Toledo. Testamento de Andrés Passano de Haro, otorgado en 4 de septiembre de 1687, ante el escribano Eugenio Francisco de Valladolid. En el archivo conventual se guarda el Memorial de la Venta y almoneda de los Bienes de Passano de Haro, 1690. Cit. en Revenga, 2002: 293. 
Bibliografía

AAVV.: La luz de las imágenes. La faz de la Eternidad. Catálogo Exposición. Alicante: Generalitat Valenciana. (2006).

Anguiano de Miguel, A./Fernández Vinuesa, P.:“La Santa Faz, una pintura singular del convento de Madres Benitas de Toledo”. En: Anales toledanos, XLV [Núm.], Toledo, (2012) pp. 153-167.

Álvarez, Ma C.: "La restauración. Recuperación de una memoria pictórica en una nueva Instancia". Colombia: Biblioteca de Luis Ángel Arango. (2009). [www.banrep.cultural.org]

Boccardo, P./Orlando, A: "Dipinti di Rubens a Genova e per Genova", En Bocardo, Piero (Ed.), L eta di Rubens: dimore, commitenti e collezionisti genovesi. Ginebra: Ed. Skira. (2004).

Bodart, D.: Rubens. Barcelona: Carroggio S.A. Ediciones.(1981)

Catálogo de la Exposición Philippe de Champaigne 1602-1674. Entre politique et dévotion. Palais des Beaux Arts, Lille/Musée Rath. Genève, 20 septembre 2007-13 janvier (2008), pp. 200-201.

Catálogo de la Exposición Rubens a Mantova. Mantova, Palacio ducale 25 settembre /20 novembre 1977. Milano, Electa editrice, (1977).

Catálogo de la Exposición Rubens. Lille, Palais des Beaux-Arts, 6 mars -14 juin 2004. París, Étitions de la Réunion des musées nationaux, (2004).

Díaz Padrón, M. y otros: Van Dyck en España. Barcelona: Prensa Ibérica. 2 vols. (2012)

Doerner, M.: Los materiales de la pintura y su empleo en el arte. Barcelona: Reverté. 6a Edición (2001).

Gállego, J./ Gudiol, J.: Zurbarán 1598-1664. Barcelona: Ediciones Polígrafa. (1976)

Garrido, C./ García Maiquet, J.: "La adoración de los Magos” de Rubens. Materiales y técnica pictórica". En La Adoración de los Magos de Rubens. Catálogo Exposición. Madrid: Ed. Museo del Prado. (2004).

Hidalgo Lucena, L.(ed.): Biografía que escribió Passano de Haro sobre el Cardenal Moscoso y Sandoval. Toledo, 1670. Toledo: Archivo de la Catedral de Toledo. (1976).

López Torrijos, R.: "Arte e historia común en el Palacio del Viso". En Bocardo, Piero/Colomer, José Luis/Di Fabio, Clario (coords): España y Génova: obras, artistas y coleccionistas. Madrid: Fundación Carolina. Fernando de Villaverde Ediciones, (2004), pp. 129-138.

López Torrijos, R.: "Sobre pintores italianos en España (Castello, Perolli y el falso Cesare Arbasia en el palacio del Viso", Universidad de Alcalá, (2007). [www. dspace.uah.es/dspace/handle-]

Mateo Gómez, I./López-Yarto Elizalde, A.: La pintura toledana de la segunda mitad del siglo XVI. Madrid: CSIC. (2003).

Martínez Caviró, B.: Conventos de Toledo. Madrid: Ediciones El Viso. (1990)

Revenga Domínguez, P.: Pintura y sociedad en el Toledo Barroco. Toledo: Junta de Comunidades de Castilla la Mancha. (2002)

Soprani, R./ Ratti, C. G.: Vite de pittori, scultori de architetti genovesi. Génova 1747. Bologna: Forni editore, 2 vols. (1969)

Vaquero Fernández-Prieto, E.: Ermita y Cofradía de San Jerónimo. Toledo: E. Vaquero. (1997) 